\title{
Pre- and post-operative symptoms of patients with stomal ulcers
}

\author{
J. HOWEL JONES ${ }^{1}$ AND M. J. S. LANGMAN ${ }^{2}$ \\ From the Department of Gastroenterology, Central Middlesex Hospital, Department of Medicine, Guy's \\ Hospital, and the Medical Research Council's Statistical Research Unit, London
}

EDITORIAL COMMENT This study of 309 patients suffering from stomal ulcer after operation for duodenal (not gastric) ulcer shows that patients with duodenal ulcer who have had a perforation are more likely to develop a stomal ulcer after operation than those who have not perforated.

Previous studies have suggested that patients operated upon for duodenal ulcer who have a previous history of perforation or haemorrhage are particularly liable to haemorrhage after operation from a proved or probable stomal ulcer (Langman, 1965). The cause of this association is unknown but there is evidence that patients of blood group $\mathrm{O}$ are particularly prone to duodenal ulcer haemorrhage (Langman and Doll, 1965), and to stomal ulcer irrespective of its symptoms (Doll, Swynnerton, and Newell, 1960); it follows therefore that if blood group is the common factor in liability to duodenal ulcer bleeding and to stomal ulcer then stomal ulcer patients in general should have an increased likelihood of duodenal ulcer haemorrhage in their pre-operative symptoms.

A retrospective analysis has therefore been made of the records of patients admitted to three London hospitals for the treatment of a stomal ulcer to determine whether they have an increased frequency of pre-operative ulcer haemorrhage compared with unselected control patients operated upon for duodenal ulcer.

\section{METHOD}

Data were extracted from the records of stomal ulcer patients admitted to three London hospitals, the Central Middlesex, Guy's, and St. James's, Balham, between 1950 and 1964, to which were added data for a few patients seen personally by us in 1965 . The diagnosis was proved at operation in $282(94 \%)$ of the 309 patients admitted to the series and in the remaining 27 a stomal ulcer was clearly seen at gastroscopy, or radiologically on barium meal

${ }^{1}$ Present address: Hospital of St. Cross, Rugby, Warwickshire. 2Present address: M.R.C. Statistical Research Unit, 115 Gower Street, London W.C.1. examination. Patients with stomal ulcer following an operation for chronic gastric ulcer were excluded from the series.

Two control operative duodenal ulcer groups were studied: these were composed of 1,195 patients operated upon at the Central Middlesex Hospital between 1953 and 1963 and a sample of 643 of the patients treated in the surgical unit at St. James's Hospital between 1949 and 1962. Apart from simple suture of perforated ulcer, details of all types of operation were taken for analysis. Patients were considered as having suffered from haemorrhage only if they had been admitted to hospital with haematemesis or melaena, the episode of bleeding could have occurred at any time before operation and was not necessarily its precipitating cause.

\section{RESULTS}

Table I compares the pre-operative symptoms of patients who developed stomal ulcers with those of the control operative duodenal ulcer patients.

It will be seen that there is a highly significant difference in the pre-operative symptom patterns of patients with duodenal and stomal ulcer $(P<0.001)$. Perforation appears particularly frequently in the stomal ulcer group, with pain or obstruction least often and haemorrhage occupying an intermediate position. With pain or obstruction taken as a base line, the relative incidence of pre-operative histories of haemorrhage and perforation in stomal and duodenal ulcer series are 1·19:1 and 1.99:1 respectively.

It can be seen from Table II that Polya gastrectomy had been performed on only $125(40 \%)$ of the 309 patients who later developed a stomal ulcer. Of the remainder, 125 had been operated on by simple gastroenterostomy, 30 by Billroth 1 gastrectomy, and 
TABLE I

PRE-OPERATIVE HISTORIES OF PATIENTS DEVELOPING STOMAL ULCERS AND OF TWO CONTROL UNSELECTED OPERATIVE DUODENAL ULCER SERIES

\begin{tabular}{|c|c|c|c|c|c|c|}
\hline \multirow[b]{2}{*}{ Series } & \multirow{2}{*}{ Hospital } & \multicolumn{5}{|c|}{ Pre-operative History } \\
\hline & & Haemorrhage & Perforation & $\begin{array}{l}\text { Haemorrhage and } \\
\text { Perforation }\end{array}$ & $\begin{array}{l}\text { Pain or } \\
\text { Obstruction }\end{array}$ & Total \\
\hline Stomal ulcer & $\begin{array}{l}\text { Central Middlesex } \\
\text { Guy's } \\
\text { St. James's, Balham } \\
\text { Total }\end{array}$ & $\begin{array}{l}19 \\
10 \\
34 \\
63 \\
(20 \cdot 4 \%)\end{array}$ & $\begin{array}{c}34 \\
16 \\
36 \\
86 \\
(27 \cdot 8 \%)\end{array}$ & $\begin{array}{c}1 \\
\frac{2}{3} \\
(1 \cdot 0 \%)\end{array}$ & $\begin{array}{c}66 \\
28 \\
63 \\
157 \\
(50 \cdot 8 \%)\end{array}$ & $\begin{array}{r}120 \\
56 \\
133 \\
309\end{array}$ \\
\hline \multirow{2}{*}{$\begin{array}{l}\text { Unselected } \\
\text { duodenal ulcer } \\
\text { operation }\end{array}$} & $\begin{array}{l}\text { Central Middlesex } \\
\text { St. James's, Balham }\end{array}$ & $\begin{array}{l}235 \\
128\end{array}$ & $\begin{array}{l}194 \\
112\end{array}$ & $\begin{array}{l}43 \\
15\end{array}$ & $\begin{array}{l}723 \\
388\end{array}$ & $\begin{array}{r}1,195 \\
643\end{array}$ \\
\hline & Total & $\begin{array}{l}363 \\
(19 \cdot 7 \%)\end{array}$ & $\begin{array}{l}306 \\
(16 \cdot 8 \%)\end{array}$ & $\begin{array}{l}58 \\
(3 \cdot 1 \%)\end{array}$ & $\begin{array}{l}1,111 \\
(60 \cdot 4 \%)\end{array}$ & 1,838 \\
\hline
\end{tabular}

Comparing the frequency of perforation and haemorrhage and pain or obstruction (excluding the group 'haemorrhage and perforation') in the combined test and control series $\chi^{2}=21 \cdot 9, \mathrm{n}=2, \mathrm{P}<0.001$.

TABLE II

COMBINED DATA OF PRE-OPERATIVE HISTORY AND TYPE OF OPERATION IN PATIENTS DEVELOPING STOMAL ULCERS IN THREE HOSPITALS

\begin{tabular}{lccccc} 
& \multicolumn{2}{c}{ Pre-operative History } \\
\cline { 2 - 6 } Operation & Haemorrhage & Perforation & Haemorrhage or Perforation & Pain or Obstruction & Total \\
\hline Polyagastrectomy & 35 & 32 & - & 58 & 125 \\
Simple gastroenterostomy & 23 & 39 & -25 & 12 & 30 \\
Billroth I gastrectomy & 5 & 7 & 1 & 20 & 30 \\
Others & - & 86 & 3 & 157 & 309
\end{tabular}

29 by other operations such as vagotomy and gastroenterostomy, but in the control series $79 \%$ had had a Polya gastrectomy, and in addition perforation was slightly more common and haemorrhage slightly less frequent in the pre-operative histories of patients with stomal ulcer who had a simple gastroenterostomy than in those who had a Polya gastrectomy. Therefore a further comparison of test and control groups divided by operation performed has been made solely for Polya gastrectomy, this being the only operative group where a large number were available for both the test and control series. The analysis has been further restricted to exclude women since they are less likely than men to suffer from either perforated duodenal ulcer or from stomal ulcer, and this difference could possibly result in a higher proportion of patients with a history of perforated ulcer appearing in the test group than in the control.

Table III shows that when the analysis is confined to male patients receiving Polya gastrectomies, the proportion with a history of duodenal ulcer perforation in the test and control group remains nearly the same as in the total series (incidence relative to pain or obstruction $=1 \cdot 87: 1$ ) while the proportion with a history of haemorrhage becomes more pronounced (incidence relative to pain or obstruction $=1 \cdot 69: 1$ ). The numbers in the test group are, however, much smaller and possibly for this reason the differences are not significantly statistically.

To determine whether the pre-operative symptoms of duodenal ulcer in patients developing a stomal ulcer tended to be the same as those of the pre- and post-operative symptoms of the 309 stomal ulcer patients the information derived from the three hospitals was combined and is analysed in Table IV. From the marginal totals for pre-operative symptoms of each type, figures have been calculated to show the numbers which would have occurred in each cell if random re-assortment had occurred to give the total numbers found with a stomal ulcer and a history of haemorrhage, perforation, pain, or obstruction. There is a highly significant difference between the results observed and expected $(P<0.001)$, which is due almost entirely to a tendency for patients with haemorrhage and pain from a perforated duodenal ulcer or obstruction to suffer from the same symptoms caused by the stomal ulcer. By contrast, patients with perforated duodenal ulcer do not show the same degree of increased risk of stomal ulcer perforating.

\section{DISCUSSION}

The results of this study suggest that patients with duodenal ulcer with a previous history of perforation 
TABLE III

PRE-OPERATIVE HISTORIES OF MALE PATIENTS DEVELOPING STOMAL ULCERS AFTER POLYA GASTRECTOMY AND OF ALL CONTROL MALE POLYA GASTRECTOMY PATIENTS FROM THE CENTRAL MIDDLESEX AND ST. JAMES'S HOSPITALS

\begin{tabular}{|c|c|c|c|c|c|c|}
\hline \multirow[b]{2}{*}{ Series } & \multirow[b]{2}{*}{ Hospital } & \multicolumn{5}{|c|}{ Pre-operative History } \\
\hline & & Haemorrhage & Perforation & $\begin{array}{l}\text { Haemorrhage and } \\
\text { Perforation }\end{array}$ & $\begin{array}{l}\text { Pain or } \\
\text { Obstruction }\end{array}$ & Total \\
\hline \multirow[t]{2}{*}{ Stomal ulcer } & $\begin{array}{l}\text { Central Middlesex } \\
\text { St. James's, Balham }\end{array}$ & $\begin{array}{r}8 \\
19\end{array}$ & $\begin{array}{l}10 \\
16\end{array}$ & 1 & $\begin{array}{l}20 \\
25\end{array}$ & $\begin{array}{l}39 \\
60\end{array}$ \\
\hline & Total & $\begin{array}{l}27 \\
(27 \cdot 2 \%)\end{array}$ & $\begin{array}{l}26 \\
(26 \cdot 3 \%)\end{array}$ & $\stackrel{1}{(1 \cdot 0 \%)}$ & $\begin{array}{l}45 \\
(45 \cdot 5 \%)\end{array}$ & 99 \\
\hline \multirow[t]{2}{*}{$\begin{array}{l}\text { Unselected } \\
\text { duodenal ulcer }\end{array}$} & $\begin{array}{l}\text { Central Middlesex } \\
\text { St. James's, Balham }\end{array}$ & $\begin{array}{l}163 \\
113\end{array}$ & $\begin{array}{r}137 \\
95\end{array}$ & $\begin{array}{l}28 \\
14\end{array}$ & $\begin{array}{l}443 \\
291\end{array}$ & $\begin{array}{l}771 \\
513\end{array}$ \\
\hline & Total & $\begin{array}{l}276 \\
(21 \cdot 5 \%)\end{array}$ & $\begin{array}{l}232 \\
(18 \cdot 1 \%)\end{array}$ & $\begin{array}{l}42 \\
(3 \cdot 3 \%)\end{array}$ & $\begin{array}{l}734 \\
(57 \cdot 1 \%)\end{array}$ & 1,284 \\
\hline
\end{tabular}

TABLE IV

PRE- AND POST-OPERATIVE HISTORIES OF STOMAL ULCER PATIENTS IN COMBINED SERIES OF THREE HOSPITALS

\begin{tabular}{|c|c|c|c|c|c|}
\hline \multirow[b]{2}{*}{ Stomal Ulcer History } & \multicolumn{5}{|c|}{ Pre-operative History } \\
\hline & Haemorrhage & Perforation & Haemorrhage and Perforation & Pain or Obstruction & Total \\
\hline Haemorrhage & $35(17)^{1}$ & 20 (23) & 1 (1) & $28 \quad(43)$ & 84 \\
\hline Perforation & 9 (8) & 13 (11) & -- & $18 \quad(20)$ & 40 \\
\hline Haemorrhage + perforation & $2(2)$ & 7 (3) & - & (5) & 10 \\
\hline Pain or obstruction & $17 \quad(36)$ & $46 \quad(49)$ & 2 (2) & $110 \quad(89)$ & 175 \\
\hline Total & 63 & 86 & 3 & 157 & 309 \\
\hline
\end{tabular}

${ }^{1}$ Figures in brackets beside the numbers actually found give the results (rounded off to give whole numbers) expected from the marginal totals for stomal ulcer symptoms if re-assortment had occurred randomly.

Comparing the frequency distributions of haemorrhage, perforation and pain or obstruction in the test and control series (excluding the group haemorrhage and perforation') $\chi^{2}=37 \cdot 96, \mathrm{n}=4, \mathrm{P}<0 \cdot 001$.

have an increased liability to stomal ulcer whereas those with a history of pain or obstruction have a comparatively low risk and those with a history of haemorrhage an intermediate risk of stomal ulcer. These findings are consistently present for comparison in the three test and two control groups, and are unlikely to be due to bias through the omission of matching type of operation and sex of patients in test and control groups, because nearly the same degree of difference is found when male patients operated upon by Polya gastrectomy only are considered. It is conceivable that a history of perforated duodenal ulcer might be asked for and noted more frequently in patients with stomal ulcer than in those having routine duodenal ulcer operations, but this seems unlikely as an explanation of the results since one might expect an equal bias to appear in the histories of haemorrhage. A final possibility is that the patients with stomal ulcer were originally operated upon for duodenal ulcer at a time when perforation or haemorrhage was considered to be a more important symptomatic indication for a definitive operation than it is now. This again is unlikely, since the proportion of patients coming to operation for duodenal ulcer with a pre-operative history of perforation or haemorrhage does not seem to have changed with time (Langman, 1965).

It has previously been shown that patients who develop stomal ulcers are even more likely to be of blood group $\mathrm{O}$, and possibly to be $\mathrm{ABH}$ nonsecretors, than are duodenal ulcer patients (Doll, Drane and Newell, 1961; Doll et al., 1960); it has also been shown that $\mathrm{ABO}$ blood group and secretor status appear to affect the clinical characteristics of duodenal ulcer (Langman and Doll, 1965). It would seem, therefore, that a common pathway could explain an increased liability of patients with perforated or bleeding ulcer to develop stomal ulcer, particularly if they were of blood group $\mathrm{O}$ or nonsecretors.

Further investigation, suggests that when the clinical characteristics of the previous duodenal ulcer are taken into account the association of stomal ulcer with blood group $\mathrm{O}$ and $\mathrm{ABH}$ nonsecretion largely disappears (Langman, Doll, and Saracci, 1967). It is therefore likely that it is the clinical characteristics of the duodenal ulcer rather than ABO blood group and secretor status of the patient which affect his liability to stomal ulcer.

The evidence showing that patients with bleeding stomal ulcer are particularly liable to have suffered from a previous bleeding duodenal ulcer confirms the more limited findings already reported on a series of patients with post-operative haemorrhage (Langman, 1965), but there is also a strong suggestion that patients with stomal ulcer in general tend to suffer 
from a similar pattern of symptoms from both stomal and duodenal ulcers.

\section{SUMMARY}

A comparison of pre-operative duodenal ulcer symptoms in patients later developing a stomal ulcer and in a control series of unselected duodenal ulcer patients treated surgically has shown a gradient of risk of stomal ulcer. Patients with perforated duodenal ulcer appear to be particularly liable to develop a stomal ulcer, patients with pain or obstruction have a comparatively low risk, and patients with haemorrhage an intermediate risk. Comparison of stomal and duodenal ulcer symptoms in the same patient suggests that they tend to show a similar pattern.
We are grateful to Dr. B. F. A. Swynnerton for his help in obtaining data from St. James's Hospital, Balham, and to Dr. Richard Doll for much helpful advice, and to the physicians and surgeons of the Central Middlesex, Guy's, and St. James's Hospitals for permission to examine their patients' notes.

\section{REFERENCES}

Doll, R., Drane, H., and Newell, A. C. (1961). Secretion of blood group substances in duodenal, gastric and stomal ulcer, gastric carcinoma, and diabetes mellitus. Gut, 2, 352-359.

_-, Swynnerton, B. F., and Newell, A. C. (1960). Observations on blood group distribution in peptic ulcer and gastric cancer. Ibid., 1, 31-35.

Langman, M. J. S. (1965). Relationship between pre-operative bleeding and perforation and bleeding after operations for duodenal ulcer. Ibid., 6, 134-136.

-, and Doll, R. (1965). ABO blood group and secretor status in relation to clinical characteristics of peptic ulcers. Ibid., 6, 270-273.

, - - and Saracci, R. (1967). ABO blood group and secretor status in stomal ulcer Ibid, 8, 128-132. 